\title{
Influencing Factors Bedeviling the Study of Science among Ghanaian Students in Senior High Schools
}

\author{
Ebenezer Wireko Brobbey ${ }^{1}$, Alexander Baah ${ }^{2}$, Sabina Ampon-Wireko ${ }^{3 *}$ \\ 1. Ghana Education Service, brobbyebenezer@yahoo.com \\ 2. Jiangsu University, School of Finance and Economics. alexbaah25@gmail.com \\ 3. Jiangsu University, School of Management Science, amponwirekosabina@gmail.com*
}

\begin{abstract}
The study unveils factors affecting the teaching and learning of science among secondary schools in Ghana. However, from open and available literature, it can be established that eleven (11) influencing factors impedes the conduct and development of science as a subject. The study aims to bring to light the factors affecting the Study of Science among Ghanaian Students in Senior High Schools. The results found that inadequate and lack of skilled science teachers, mode of delivery of science, Lack of Resources, changing of policies affect the teaching and learning of science. The study however posit various innovative measures and methodologies that policy makers can adopt towards improving the teaching of science as an academic discipline in the country.
\end{abstract}

Keywords: Science, Education, Ghana, Senior High Schools

DOI: $10.7176 / \mathrm{JEP} / 11-9-28$

Publication date:March $31^{\text {st }} 2020$

\subsection{Introduction}

Curriculum development principles and practices are established guidelines governing the teaching and learning of science. The curriculum is considered to be the assigned interaction of learners with the prescribed content, materials, resources and process of evaluating educational objectives (Luke, Weir, Woods, \& Moroney, 2008). These steps include the use of literacy's and demagogies that are intertwined with the use of media or text that solve the difficulties of learning. This includes statements of desired learner results descriptions of the material and planned activities that will be used to help learners achieve the results.

Curriculum development on the other hand is the set of organized preparation of whatever is going to be taught in schools at a given period (Kiani, Ghazanfarpour, Yazdanparast, \& Saeidi, 2019). They are put into official documents as guides for teachers and made obligatory. In the teaching of science, curriculum materials and instructional strategies ideally should be channeled to the abilities and aptitudes of different types of learners. The overall objectives should be created on learning environment which allows student to interact physically and intellectually with instructional materials through "hands on" experimentation and "mind-on" reflection. In Ghana, the Ministry of Education recommends the syllabus and textbooks for almost every child but teaching and learning varies from urban, urban-rural, community- based and deprived schools.

\subsection{The general focus of science as a compulsory subject in Ghana}

The Ghanaian science curriculum in the form of a syllabus is designed to help the student to:

1. Addressing fundamental problems around his/her immediate environment by way of analysis and experiment.

2. Ensuring a proper balance of the diversity of living and non-living things through the study of their interconnectedness and repeated patterns of change. Practice sustainable habits for safeguarding the natural environment for humans and society.

3. Using simple tools and equipment's effectively with better understanding of their underlying principles and underlying operations.

4. Identifying, preserving and optimizing the benefits of energy as essential resources for the world.

5. Use scientific way of life based on careful observation and investigation of events. 
6. Searching for solution to the challenges of life by recognizing the interaction of science, technology and other discipline.

In Ghana, science education must be taught to reflect what is enshrined in the National science and Technology policy. A policy that was adopted in 2008 but has not been implemented. The vision of the broad National Science and Technology policy in Ghana remains the broad National vision of middle in-come status of an advanced society with better quality life reflected in all aspects of socio-economic and environmental conditions (Sayed, MacKenzie, Shall, \& Ward, 2008). In practice, Ghana must seek a future of science, technology and innovation policy which enables maximum production and processing of national resources that she is blessed with, while also developing a natural engineering and manufacturing capabilities consistent with the skills and talents that is able to harness and be among of the competitive world community.

The remaining sections of this article are organize into three parts. In sections 1 , related studies relevant to article are discussed. Section 2 highlights the innovative ways to promote the study of science and the last section gives the conclusion and policy recommendation of the study.

\section{2, Literature Review}

The goal of science, Technology and Innovation (STI) policy which is fully, integrated into a natural developments strategy which fully harnesses the nation's total science and technology capacity to achieve national objectives for wealth creation, poverty reduction, competitiveness of enterprises, sustainable environmental management and industrial growth (Owusu-Nimo \& Boshoff, 2017). In the long-term, the main objectives are to create endogenous science and technology capacities appropriate to natural needs, priorities and resources, and to create a science and technology culture whereby solutions to the socio-cultural and economic problems of the individual Ghanaian community and the nation as a whole is recognized and sought within the domain of science and technology. The effective implementation of the Science and Technology policy will be guided by the following principles; relevance, cost effectiveness, realism, synergy, partnerships, job and wealth creation, demand-driven potential and sustainability (Owusu-Nimo \& Boshoff, 2017).

In the education section the STI is to orient all aspect of the country's education system to the teaching and studying of science and technology so as to produce a critical mass of the requisite scientific human resources for national development and accelerate the acculturation of science and technology society.

Ghana is considered to be the first independent sub-Saharan African country aside South Africa to begin a comprehensive measure to promote science education and the use of science in industrial and social development. One may ask what went wrong with science education and science in Ghana. Even though on paper the curriculum for science education appears to be perfect, in reality that is not what it is, it has been seen that, the rate of scientific literacy among the youth who constitute about 44 percent of the Ghanaian population is low and that of the adult is even lower (Barke, Nyarko, \& Klecha, 2011).

Environmental hygiene has become a social canker, heaps of plastic waste materials are found in and around major towns, drainage systems are choked with plastic waste materials (Addy, 2013). Malaria is recorded as the highest rate killer disease in the country but we tend to look on almost helplessly to the damage being caused by malaria parasite, forests reserves are dwindling rapidly because of deforestation, illegal harvest of tress, illegal mining and bad farm practices.

The solutions to the situation stated above lies in the development and implementation of effective science and technology at all areas of our education system, especially at the basic level. Such a curricular should build the strength of innovation and change that leads people to come out with ideas and search for better ways of doing things. On the other hand, the present practice of science education in our schools does not give the enabling environment for training the human and social capital needed for national development. Many factors militate against the proper way of teaching and studying of science in our school. These factors bedeviling the study and learning of science are what authors have categorized and discussed below; The science teacher, the content, methods of delivery, resources, funds, individualism, pedagogy of science, politics, the point of environmental education, science as civic and peace education etc. The interactions of these points listed above in the end will results in student's performance. Inadequate provisions will result in inappropriate performances by the learners. 


\subsection{Factors bedeviling the Ghanaian's science education \\ The science teacher}

The science teacher is the main person who facilitate in the proper teaching and learning of science, in Ghana, especially at the pre-tertiary level, there are no enough teachers trained to handle the sciences, some of the classrooms are filled with teachers who are trained in other areas of specialization instead of education in science. Economic hardship influences the mismatch of profession but among the few trained teachers to handle science as a subject are not motivated enough to work effectively. For instance integrated science is taught in all level of pretertiary level in Ghana but there are about only 500 teachers who are specifically trained to teach integrated science (Anderson, 2006). This has force teachers who are train in other areas to teach integrated science.

These instructors may lack the request skill of integrating the sciences and may teach integrated science as elective science (physics, chemistry etc.). Currently, some teachers have worked for couple of months if not years and have not been paid a penny for their sweat and effort of impacting knowledge (Singh, 2006). This de-motivate teachers especially science teacher when it comes to attending various important seminars, conduct research, travel to places to observe activities etc. The repercussions of these problems has generational effect. It is not surprising that the country lags behind major developing countries like be like Finland, Canada and South Africa where science teachers are taken very good care of in terms better salaries and wages with good remuneration, these countries also provide regular in-service training for its teachers.

\section{The mode of delivery of science}

Currently in Ghana, basic science is taught in abstract without any laboratories where students can use instruments and apparatus. The "hard-to-say-truth" is that well-established schools with modern facilities and laboratory also lack the knowledge and expertise to assist student to conduct research into current environmental phenomena. The Ghanaian case is in sharp contrast to what Reindekard said about science that "science is hands on activities" the teaching of science in Ghana is teacher centered (Beisenherz \& Dantonio, 1996). That is the teacher is most of the times at the center of the teaching instead of the student being at the center. When this happens, it will be very difficult to inculcate scientific knowledge into learners. The teachers' role in the teaching and studying of science is to be a facilitator and act as a guide. But in the Ghanaian contest, the exact opposite is practiced.

That is, our teaching and studying of science does not allow the students to explore and come out with their own meanings. Our system of teaching core science does not allow student to explore, experiment and interact with their environment even though that is what is enshrined in the core science syllabus, but actually, that is not what is been practice in our school (Green, 1998). What is practice in Ghana can't be compared to countries like Russia where the teaching and studying of science at the formative stages allow learners to explore their environment in the learning of science.

\section{Lack of Resources}

For proper teaching and studying of science to occur there must be resources available for teaching and learning but in Ghana resources are not available for the teaching and studying of science in schools. Infrastructure, laboratories, workshop, etc. are lacking in some schools in Ghana. These basic things are the equipment for effective teaching, learning and developing inquiring skills and innovative capacity of students across the different levels of schools. Lack of aforementioned facilities make teaching and learning of science difficult. In comparison, countries like, china spends about 7 billion on quality education, support for science and technology education and research and development, in Finland there is LUMA program that improves mathematics and science education through formation of network of schools and institutions, in-service education and teacher education (Wikipedia, 2019).

\section{Politics (changing of policy)}

In Ghana there is much political interference in the education system. Thus, one government want to change the Senior High School to four years while another government wants to change to three years, government do not provide for what is needed for effective studies of science. Researches are made on issues concerning education in Ghana and politicians choose not to implement them because it does not fall in line with their ideology. An example is the non-implementation of the National Science policy. This is because the politicians are not ready to spend much, so their refusal to make effort in implementing it (Daw \& Gray, 2005). When this happens, it affects the study of science and disrupts scientific activities, because there must be continuity in science.

Too much political interference in Ghana education violate the core principle of science which states that science is tentative and repeated observation as propounded by Francis beacon which implies that if government keeps 
changing science polices every four years it means, we cannot study the repetition of science for longer periods to make scientific deductions (Sen, 2004). This can't be compared to a country like Israel where every education on science is guided by Israel national science policy that stipulates that science and technology is to be used to cope with the problems of modern age and to ensure a better quality of life for all citizens.

\section{Lack of policy direction for science education}

Ghana even though have a drafted national science policy, the law is yet to be approved by parliament. When a country implementing science with no national science policy that stipulates the direction for the teaching and studying of science. Teachers find it difficult to teach to meet the aspirations of science in the country. This can be compared to countries like Israel and China where science and technology is very important and its enshrined in their national science policy. This is because science and technology are used to cope with the problems of modern age and to ensure a better quality of life for all citizens, where science and technology is the foremost productive force respectively.

\section{Lack of Funds}

There is less funding to outgrow science education in Ghana. It is estimated that resources allocation to science and technology education constitute 0.25 percent of GDP which is greatly below the decision taken by the signatories to the Lagos plan of actions to spend 1\% of Gross Domestic Product (Amankwa and Mubarik,2018). This has resulted in poor infrastructure including laboratory and workings materials for teaching and learning of science in Ghana schools. This cannot be compared to countries like South Africa that spends 0.732\% of GDP while Israel, USA and the countries of the European Union allocate $4.9 \%, 2.744 \%$, and $1.64 \%$ on the average of GDP respectively on only research (Wikipedia,2018).

\section{Pedagogy}

The Ghana Science education, especially integrated science is perceived irrelevant content. Teaching pedagogies do not support critical thinking and problem solving, content is also not connected to issues in the environment of the learners. Science is then learnt as uninteresting subject but seen as gathering of abstract facts. These have made students and Ghana citizen not to see the benefits of science. This cannot be compared to various countries especially Netherlands where students are required to assume responsibilities for their own science learning. According to research conducted by (Gibbs \& Simpson, 2005) Dutch students learn science by working independently, often on assignments instructing them to read and write more. Students are required to check their own long-term assignment and to also monitor their work as they progress.

\section{The issue of Environmental education}

The environmental science aspect that is embedded in the core science curriculum is about knowing what the environment is but not what real the environmental is. In order to maintain the study of science in various schools, it must stress on the need to include and help young learners to engage in environmental science knowledge. This education must stress on the interdependences of society, culture, and nature and necessity for living communities to stay "harmony with their physical environment for collective survival.

For example, science education must teach about traditions, local traditions of sustainable environmental resource use and particular cosmological beliefs system and world views that herald the holiness land and physical environment. We need critical science education that protects and capable of sustaining the environment for current generation and the generation yet unborn. The Ghanaian integrated science does the exact opposite. It just impact knowledge about working of the biosphere. This cannot be compared to a country like Indonesia where their science education is in line with their culture, religion and God (Stepan, 2000).

\section{Science as civic and peace education}

Ghana's science education does not recognize science education as civic and peace education. It is only thrived on theories. It does not recognize that for science to be effective and attractive to students, it must promote civic and peace education. For example, indigenous science knowledge and teachings relatively to Ghana proverbs that highlight on the youth moral character development, a knowledge of civic responsibility, community building, citizenship and a community. If service education fails to recognize this, as happening in Ghana; nothing meaningful can come out of it.

\section{Individualism}

One serious causative factor that is bedeviling the Ghana science education at the basic level is the failure to realize the need of team work approach/ cooperation. The syllabus of core science laid emphasis on the individual student 
instead of placing much emphasis on team work and co-operation (team learning), without team work advancement would be much slower and at a standstill with regard to the theory analysis of a perplexing challenging question. Ghana is having so many problems in terms of science because the SHS science education does not build students in teams to find quick solutions to our basic problems.

This cannot be compared to a country like Russia where the study of science is for the country but not for the individual learners. Russia does this by always putting the country first. This has made citizens in Russia to work in groups to find solutions to the challenges of Russia by means of science. The alternative way to solve these challenges bedeviling the Ghana science Education. The measures for the country's development is promotion of science education especially at the pre-tertiary level, is not just science alone, but science coupled with the character of innovation.

Science do not foster character of innovation and the change in students, the country's development depends on the understanding and usage of science and capacity to conduce to the innovation and change.

\subsection{Attracting and retaining high quality science and technology teachers}

Promotion of science education in the country will rely on the diverse factors. These factors are discussed below

\section{Motivation}

Strengthening the teaching of science and technology in the schools will require consideration of the preparation, continuing professional learning and improvement in the conditions of service of teachers. Quality teachers make a difference. They are the single most important determinant factor of student performance. They are the ones who manage the resources, adopt appropriate delivery methods and interpret the content of the curriculum. We need skillful teachers to teach science and technology. Those entrusted with the responsibility to sustain scientific and technological understanding, inquiry and developing innovative capacity in the youth and must be knowledgeable, skillful, actuated and committed. They will be expected to build in students and themselves the spirit of creativity, imagination, original thinking, open-mindedness and critical thinking.

Teachers should help students to be innovative by helping them to find appropriate ways of doing things. Teaching of science and technology in particular should attract the best of students from the senior high level. This cannot be the case as at now even though, in the 1960s science teacher received preferential treatment. The salary and other conditions of service should be improved to make the teaching of science a career of choice. As indicated, teachers should be provided with the opportunity to undertake continuing professional learning so as to update their knowledge in their subject areas.

\section{Resources allocation}

Resources like science laboratories, resource centers, textbook, and laboratory equipment must be readily made available for proper teaching and learning of science in Ghana. We can even provide well equipped moving laboratory vans to move to areas that have no laboratories for learning science. Many nations are spending millions of dollars to introduce sustainable initiative in science and technology.

\section{Funding}

Knowledge is not cheap. Science knowledge requires moving the country into knowledge society and this can certainly not be cheap. Government commitment to science education must be demonstrated in the amount of resources allocated to science. Laboratories and workshops in schools should be well equipped and the new ones yet to be constructed should consider the increasing number of student population. Funds should be provided by the various stakeholders like the government for research since the knowledge society thrives on the creation of new knowledge. Research provides the means by new discoveries is created. Resources both material and human are needed for research. There must be a need to provide funds for research. If Ghana wants to really make it in science then, we must raise our current financial allocation for science to $1 \%$ GDP as practice in countries where allocations for research alone supersedes this (Alexander, 2000).

\subsection{Conclusion and Recommendation}

In conclusion, the dictate of our age poses a great challenge not to only the country but more importantly to us as teachers of discipline science, stakeholders ought to change both what used to be a decade ago and the best possible means where necessary. The science curricula must provide a space for the indigenous communities and culture to evolve. Such a space can only be produced when government unlock the barriers towards accepting and broadly 
revising science training and equip school with the modern facilities and opportunities to confront dominant paradigms and academic reasoning. The young constitute a significant resource that can be train to hold the rains of the country effectively through science and technology education. Generally, the government, policy makers and the Ministry of Education must collaborate to make study of science interesting and a reality.

\section{Policy Direction for Science and Technology Education}

The production of well-informed citizens with the capacity to solve problems, to create and generate new ideas and best ways of doing things will increasingly depend on a unifying vision and focus on education in science and technology. Such a policy direction should ensure the cultivation of a mores of innovation in the school, facilitate professional learning, and lay emphasis on partnerships and networks with domestic and outside agencies to boost quality and breadth of learning. It must also address the three goals of science education; production of research scientists and technologists, people for science and technology vocations and creating scientific and technological awareness among the masses.

It is believed that the only way to improve the meaningfulness of science and technology education to people is to allow community culture and knowledge to contribute to its content and delivery. Science content tends to underestimate the potential of inherent knowledge and practices. In a good number of cases the practices in the schools have a propensity to marginalize such knowledge thus making science and technology abstract and foreign to the Ghanaian student.

However, local practices such as gari production, palm kernel oil extraction, beads manufacture, food processing, salt production, preservation practices and housing construction constitute a rich source of science and technology ideas which can be used to enrich teaching and learning. In addition, a study of science and technology concepts embedded in modern industrial activities in the country can also generate meaningfulness.

The ascendancy of the banking approach to teaching that is manifested with the use of lecture, chalk-and-talk, and demonstration will not help in developing the inventive potential of students. Schools are required to implement educational practices that help to cultivate in students the ability and predisposition to be innovative. There is therefore the call for teachers to shift from teacher and curriculum centered teaching to student centered approaches. As an alternative of viewing learning as a process of accumulating bits of information, it ought to be seen as the active construction of knowledge by the learner.

Students must be encouraged to carry out scientific investigations and project work both as individuals and in groups. Schools ought to be encouraged to form science and technology clubs, organize visits and attachment to community resources such as manufacturing and research laboratories. Personnel from industry and commerce can be engaged to give talks in their special areas and mentor young learners.

Much emphasis should be placed on the country Ghana (team) than on individual students. When this is done students well all the time have a logic of responsibility to come together in using science in finding solutions to the countries enormous challenges. Our assessment must not only be based on only paper and pencil test, it must include other form of assessment that will develop in students the skill to be critical thinkers. This will also cater for students who may possibly not be the traditional chew and pour type to also add to the knowledge of science.

Ghana science curriculum must bring local, cultural knowledge into school science education. This will demand that we reorganize some of our held reservation about cultural reforms. As we move forward in educating young learners for tomorrow, we have to come to grips with key questions about science education that implicate spiritual knowing. How do we teach local cultural knowledge as indigenous science, that emphasis a physical and metaphysical interdependence and connection? How do we approach the teaching of spiritual identity as way of knowing in the schools? There is the need of creation of "tribalistic space" in schools. This space will constitute as a space for learners to openly utilize the body, mind, and soul/spirit. Indonesia is practicing this approach. That is Indonesia has placed God at the center of all their education including science and it is working perfectly for them so Ghana can learn lessons.

There is the need to review the science curriculum to make it receptive to the infusion of ICT as a means of elevating the content of what we teach. We equally need to change the pedagogy to mirror the change in the curriculum and the dictate of the information age.

Ghana must set up a formal scheme for mentoring the Youth- This is critical to the development of a career path in science for the youth. Mentors excite interest in junior colleagues and aid them to "walk the path". This 
experience is however rare in the universities. These days, newly recruited scientists struggle to keep afloat with small or no support. A formal mentoring system should be established in all institutions to guarantee that young scientists recruited into the universities or research institutions are attached to professors and higher-ranking scientists in their fields of study to receive advice and support. The mentoring can take the form of joint research, publications and presentations at conferences and seminars. With the SMART MOVE, teachers and students can literally pick up words and move them to new locations they physically pair pictures with definitions or categories, it also allows learners to interact with other science students with the use of the internet by just touching the screen of the white board. This project will involve encouraging schools through visits, presentations and seminars to work on problem solving projects with support from the community. The projects will be assessed and students with innovative and creative projects will be invited to present their projects at a Junior Scientist Conference which will be attended by senior scientists who can later act as mentors for the students. Prizes will be given to students based on the excellence of project and presentation. The Ghana Academy of Science and Arts can take up this.

\section{References}

Addy, N. (2013). Assessing the Effects of Uncollected Waste Generated by Households in Tema Newtown. University of Ghana,

Alexander, F. K. (2000). The changing face of accountability: Monitoring and assessing institutional performance in higher education. The journal of higher education, 71(4), 411-431.

Anderson, I. K. (2006). The relevance of science education: As seen by pupils in Ghanaian junior secondary schools. University of the Western Cape,

Barke, A., Nyarko, S., \& Klecha, D. (2011). The stigma of mental illness in Southern Ghana: attitudes of the urban population and patients' views. Social psychiatry and psychiatric epidemiology, 46(11), 1191-1202.

Beisenherz, P., \& Dantonio, M. (1996). Using the Learning Cycle To Teach Physical Science: A Hands-on Approach for the Middle Grades: ERIC.

Chung, J. (2019). PISA and Global Education Policy: Understanding Finland's Success and Influence: BRILL.

Daw, T., \& Gray, T. (2005). Fisheries science and sustainability in international policy: a study of failure in the European Union's Common Fisheries Policy. Marine Policy, 29(3), 189-197.

Gibbs, G., \& Simpson, C. (2005). Conditions under which assessment supports students' learning. Learning and teaching in higher education (1), 3-31.

Green, A. (1998). Core skills, key skills and general culture: in search of the common foundation in vocational education. Evaluation \& Research in Education, 12(1), 23-43.

Kiani, M. A., Ghazanfarpour, M., Yazdanparast, A., \& Saeidi, M. (2019). Curriculum Development in Pediatric Education: A Systematic Review â. International Journal of Pediatrics, 7(3), 9197-9205.

Luke, A., Weir, K., Woods, A., \& Moroney, M. (2008). Development of a Set of Principles to Guide a P-12 Syllabus Framework. A report to the Queensland Studies Authority.

Owusu-Nimo, F., \& Boshoff, N. (2017). Research collaboration in Ghana: patterns, motives and roles. Scientometrics, 110(3), 1099-1121.

Sayed, Y., MacKenzie, I., Shall, A., \& Ward, J. (2008). Mainstreaming higher education in national and regional development in Southern Africa: A regional profile. In: SARUA, Pretoria, ZA.

Sen, A. (2004). Elements of a theory of human rights. Philosophy \& Public Affairs, 32(4), 315-356.

Singh, D. (2006). Emotional intelligence at work: A professional guide: Sage.

Stepan, A. C. (2000). Religion, democracy, and the" Twin Tolerations". Journal of democracy, 11(4), 37-57.

Tait, A. A., \& Heller, P. S. (1982). International comparisons of government expenditure (Vol. 10): International monetary fund.

TERKPER, S. E., \& MAHAMA, H. J. D. THE BUDGET STATEMENT AND ECONOMIC POLICY. 